\title{
What do school children want from sex education?
}

\author{
Abigail Lewis-Barned
}

\section{Background}

In December 2008, in my second year as a medical student at the University of Bristol, during a student-selected component (SSC), I was part of a project in 'Peer Led Sex Education'. The course involved learning about sexual health and relevant areas such as sexually transmitted infections (STIs), unplanned pregnancy and contraception, working on various projects and eventually preparing and delivering sex education to Year 9 (aged 13 years) children in a local school. The plan was that my fellow students and I would deliver this programme at the beginning of the next academic year. We were taught the relevant information by doctors who worked at the Bristol Sexual Health Centre and we developed our own lesson plans for delivery in the school. As part of the preparation for this exercise we evaluated the teaching that had been delivered by previous students on this SSC with the aim of modifying our future teaching strategy accordingly.

\section{Evaluation of previous teaching methods}

Our evaluation involved administering a questionnaire to the pupils who had already received the sex education sessions. This questionnaire identified strengths and weaknesses of the previous teaching and helped to guide the development and delivery of our own lessons. This was useful, not just for our own lessons later that academic year, but also for developing principles regarding delivery of sex education in other schools. Given the time and culture we live in, we have a duty to deliver clear and informative sex education, and as such we need to ensure that our teaching is of the highest standard.

We designed our questionnaire as a group, using 44 questions to assess various aspects of the pupils' opinions of the teaching, and their retention of information. We used a mixture of open and closed questions to do this. We were keen to identify the areas in which the pupils failed to remember information, or were currently misinformed.

We gave the questionnaire simultaneously to 88 of the 120 pupils who attended the teaching sessions. Pupils were absent at random on the day the questionnaire was administered. We have no reason to believe that the pupils who missed filling in the questionnaire were any different from those who completed it so we consider the results to be representative of the entire group receiving teaching.

\section{Data analysis}

We used the Google ${ }^{\mathrm{TM}}$ Spreadsheet \& Forms web application to gather the information together and then carried out univariate and multivariate analysis of the data using the Excel ${ }^{\mathrm{TM}}$ spreadsheet application and the $\mathrm{R}$ statistical analysis package.

The respondents were almost evenly divided between female $45 \%(40 / 88)$ and male $55 \%(48 / 88)$. We found no statistically significant gender differences between the responses and thus we did not consider this further in our

J Fam Plann Reprod Health Care 2010; 36(2): 93-96

(Accepted 25 November 2009)

University of Bristol School of Medicine, Bristol, UK Abigail Lewis-Barned, Medical Student

Correspondence to: Ms Abigail Lewis-Barned.

E-mail: abbylewisbarned@gmail.com

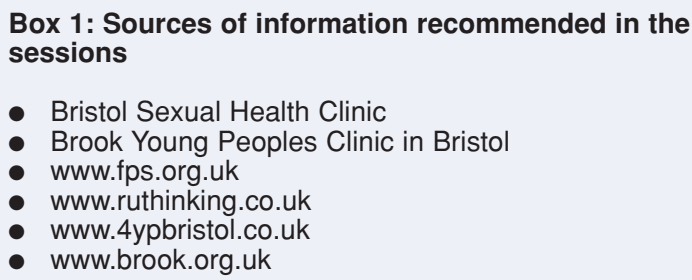

- Bristol Sexual Health Clinic

- Brook Young Peoples Clinic in Bristol

- www.fps.org.uk

- www.ruthinking.co.uk

- www.4ypbristol.co.uk

- www.brook.org.uk

analysis. The sample size was small and ideally, in future years, as the programme develops and grows, more responses will be available for analysis, thus allowing us to identify any gender differences in the responses. We analysed the responses on a question-by-question basis, giving our recommendations for improvement.

\section{Opinions on teaching methods}

The teaching was divided into three sessions: (1) Sexually Transmitted Infections, (2) Contraception and Unplanned Pregnancy and (3) Risky Behaviour.

Initially, we asked pupils for their opinions on the amount of information taught to them and almost half of them felt that too much information was presented in each session. In future the amount of information taught per session should be reduced and the focus should be on repetition of the most important facts and advice. Further information can be sought if desired from the sources we recommended to the pupils (Box 1).

Since the teaching was delivered by medical students, rather than by teachers or other health care professionals, we wanted to assess how this was perceived by the pupils. The majority (84\%) of respondents were positive (with $12 \%$ unsure and $4 \%$ negative), suggesting that this was one of the strongest points of this programme (Figure 1). As medical students, we were perhaps able to bridge the gap between the pupils and older health care professionals, hopefully gaining the respect of the pupils due to our knowledge as doctors in training, as well as using to our advantage the smaller age difference, and ability to relate to the pupils' youth. As we were detached from the school, we were also able to remove some of the fear and embarrassment that pupils may feel when talking to teachers. This was reflected in comments from pupils such

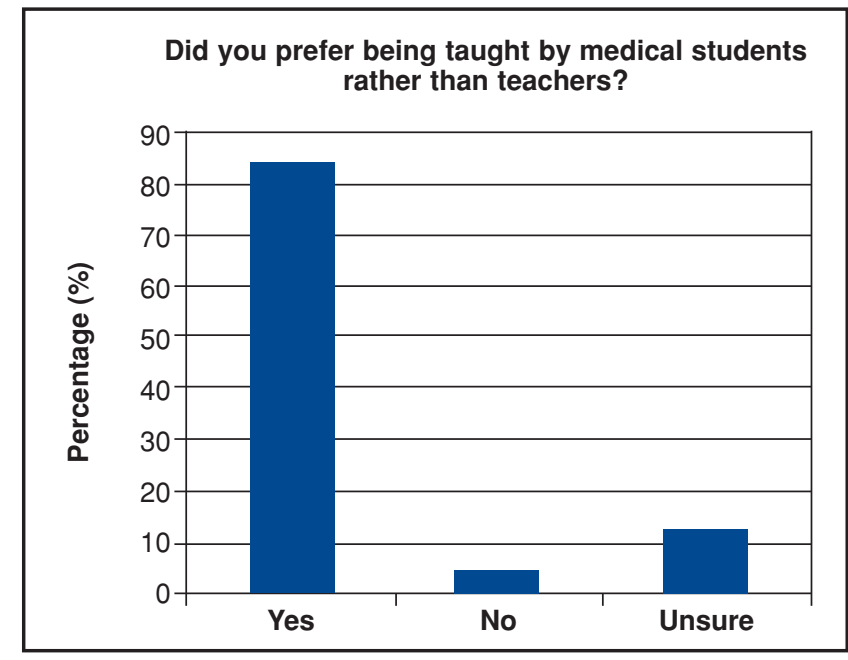

Figure 1 Respondents' answers to the question 'Did you prefer being taught by medical students rather than teachers?" 
as "because they're younger and they explain it in a way which aids your understanding", "it was easier to relate to them", "because they are closer to our age" and "because a teacher will be in the school and medical students won't be there [after the teaching], it makes it less awkward".

Pupils also liked the interactive nature of the teaching, which was achieved through group work, discussion of case studies and practical demonstrations, such as putting a condom on a plastic penis following a demonstration. We felt that this component of the teaching programme should be maintained and if possible increased, with future sessions aiming to find new ways in which the pupils can interact informally both with each other and with the medical students during the teaching.

\section{Knowledge retention}

The second section of the questionnaire aimed to assess the accuracy with which pupils retained knowledge from the teaching sessions. We did this by asking questions such as "What is the most common STI?" This highlighted some weaknesses in our teaching since only $55.7 \%$ (49/88) of pupils correctly chose the most common STI (chlamydia). Whilst knowledge of statistics per se is not of primary importance, this section of the questionnaire identified specific gaps in the pupil's knowledge. In future we should ensure that not only is accurate teaching delivered, but that the most important messages are repeated throughout the session, summarised at the end of the session, and again at the beginning of the next session. Regarding where to seek STI testing, $84.1 \%(74 / 88)$ of pupils gave an acceptably correct answer (i.e. any medical service capable of providing or referring on to STI screening). Only $10.2 \%$ of pupils suggested the Bristol Sexual Health Clinic. We suggested that in future teaching the Bristol Sexual Health Clinic be promoted more heavily as one of the most appropriate places to seek free, confidential and comprehensive sexual health and contraceptive advice services.

We included multiple-choice questions for possible "routes of transmission of STIs", which the pupils had to identify as true or false. This area was covered in the teaching because previous SSC students had wanted to use this opportunity to dispel some of the myths surrounding sexual health.

\section{Knowledge about contraception/ emergency contraception}

To assess teaching on contraception we asked questions such as "What is the most effective form of contraception?" and "How many days after unprotected sex can emergency contraception be used?" We also asked how confident the pupils felt about putting a condom on properly (Figure 2).

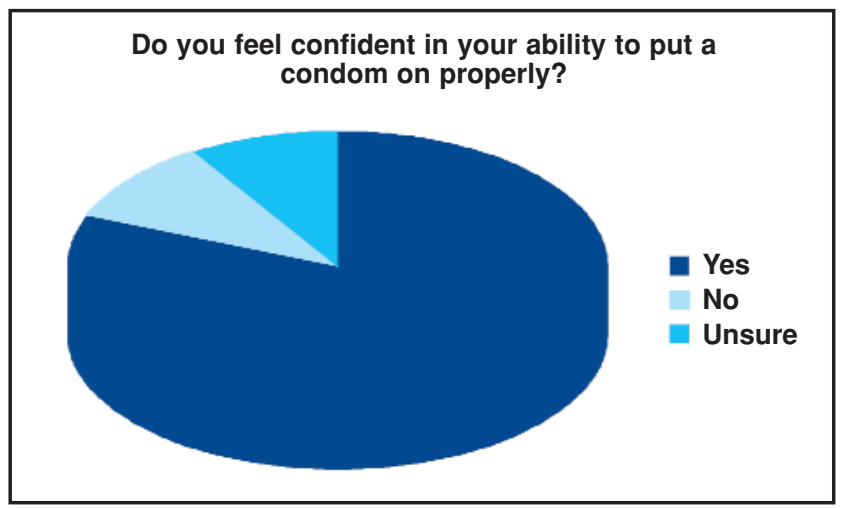

Figure 2 Respondents' answers to the question "Do you feel confident in your ability to put a condom on properly?"
Whilst confidence is not necessarily directly related to competence, we felt it was important to try to determine whether the pupils themselves believed the teaching was satisfactory, and this was also a way of assessing one of the practical elements of a class.

The most effective form of contraception, the subcutaneous hormone implant, was successfully identified by $77.3 \%(68 / 88)$ of pupils, and $90.9 \%(80 / 88)$ of the respondents could correctly identify at least one form of emergency contraception. Only $2.3 \%(2 / 88)$ of pupils did not know any methods. Incorrectly reported forms of emergency contraception included "stairs", "coat hanger", "X-rays to delete the baby", "condoms" and "the withdrawal method". Despite the fact that some of these answers were clearly intended as jokes, we did feel that future teaching should highlight the dangers of trying to abort a pregnancy without medical advice or intervention, and should also clarify the distinction between contraception, emergency contraception and abortion.

Pupils commonly (29.6\%) suggested 3 days as being the number of days after unprotected sex during which emergency contraception can be used. This was not our anticipated correct answer; this may be due to the phrasing of the question, or confusion as we were taking into account the opportunity to get an intrauterine device (IUD) fitted up to 5 days after unprotected sex, rather than simply the emergency contraceptive pill. The answer "5 days" was selected by only $12.4 \%(10 / 88)$ of respondents. The remaining $61.4 \%(54 / 88)$ of pupils answered incorrectly (neither 3 nor 5 days), indicating that there is a need to explain more clearly the timeframe associated with the emergency contraceptive pill and the IUD in future teaching. We felt that this was a particularly important piece of information for the pupils to retain, given the sense of urgency in seeking emergency contraception in the case of unprotected sex.

\section{Targeting teaching according to gender}

One of the issues surrounding sex education in schools that we discussed was whether it would be beneficial to split teaching into same-sex groups, thus allowing pupils to ask questions that they might not be comfortable asking in front of their peers of the opposite sex. We asked this as one of the questions and the response was in favour of keeping the classes mixed (Figure 3 ). This does of course allow communication of different opinions and ideas, possibly helping the pupils to understand the views of the opposite sex.

The majority (80\%) of pupils thought that the content was correctly targeted at their age group. The remaining $20 \%$ claimed that they had already been taught the material

\section{Would you rather have the teaching separated into girls and boys?}

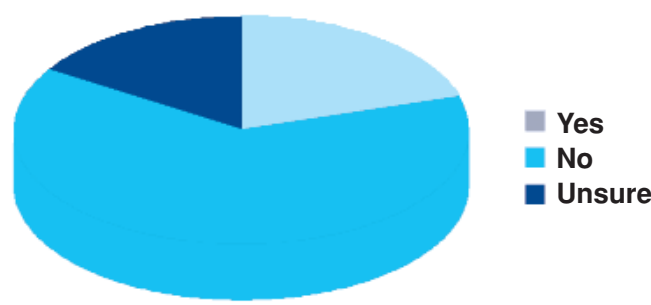

Figure 3 Respondents' answers to the question "Would you rather have the teaching separated into girls and boys?" 


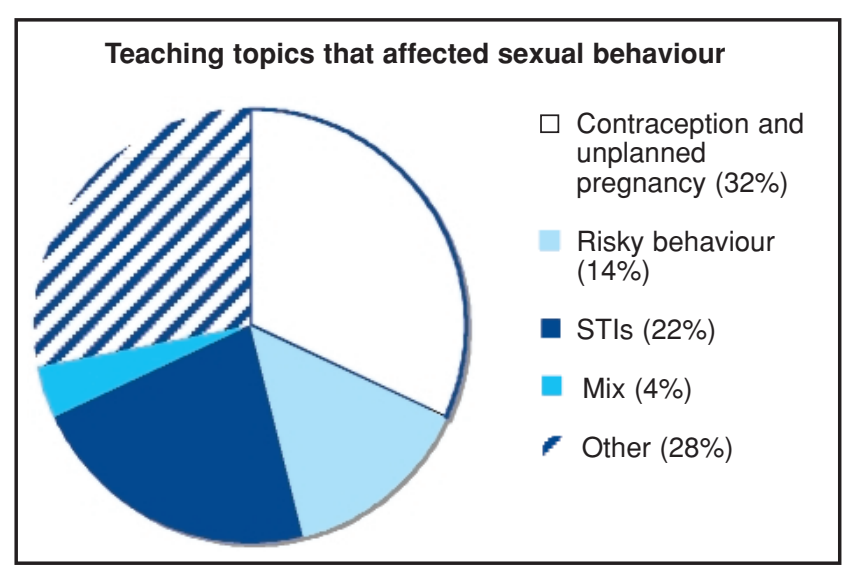

Figure 4 Respondents' views on teaching topics that affected sexual behaviour. STI, sexually transmitted infection

and so weren't learning anything new. When questioning the pupils on the day we delivered the questionnaire, they said that they had already received sex education twice before. The pupils who felt the sex education wasn't being targeted at the correct age group said that it was too late as some of them were already sexually active. It may be more effective to amend the material included in the programme in order to expand the pupils' knowledge rather than start with the very basic facts, as this information may be repetitive for some of them. However, the fact that some pupils are already sexually active makes sex a very relevant issue at their age, and so learning more about it now rather than earlier might mean that they pay more attention.

\section{Relevance of teaching}

We asked whether the pupils believed they had learned something from the teaching material that has, or will, influence their future sexual behaviour, and to identify this, and $56 \%$ said they had. Responses were then coded into five topics to identify the area of teaching responsible. The five options included the three different teaching sessions ('Sexually Transmitted Infections', 'Contraception and Unplanned Pregnancy' and 'Risky Behaviour') as well as 'Mix' representing two or more of the sessions and finally the category of 'Other' for those pupils who didn't respond or who gave a response that could not be categorised into any of the other four categories. The results are shown in Figure 4.

The 'Contraception and Unplanned Pregnancy' session had the greatest effect on the pupils, suggesting that the topics addressed in this session were the most relevant to them. This may reflect the "It won't happen to me" attitude that many young people have towards STIs, in contrast to contraception, which is clearly relevant to anyone in a sexual relationship. This of course only related to the $56 \%$ of pupils who answered 'Yes' to the first part of the section and does not include the remaining $44 \%$ whose future sexual behaviour was not affected.

Having given advice about services where pupils could go for advice or help, we wanted to assess whether we had changed their immediate and future behaviour patterns. To assess change we first asked them whether they would have used available services such as the Brook Clinic or the Bristol Sexual Health Centre before the teaching. About $40 \%$ said they would not have used the services, $41 \%$ said they would if required, $3 \%$ said they had used them before and $16 \%$ said they were unsure. We wanted to assess the barriers that young people may have to approaching these services, so we then asked them to explain their choice if they had said they would not use them.

The most common reason for not using the services in the past was lack of knowledge of their existence (65\% of those who answered 'No'). Thus we can be confident that we have at least helped break down one of the barriers by providing information about available services. One-fifth $(20 \%)$ of the pupils said they did not feel the need to use the services and some gave reasons such as religious beliefs. One of the major fears surrounding these services, highlighted by $15 \%$ of respondents, was the embarrassment of going to them and asking for help, including fears that their treatment would not be kept confidential, particularly from their parents.

Asking these questions also gave us an indication of the proportion of these pupils who are using the services and thus to whom the teaching is currently significant. Despite the fact that it was a small percentage of the total sample, it does indicate that it is relevant to deliver the teaching at this age.

We also asked pupils whether they would use one of the services now, since the teaching, and again to give reasons if not. This time $73 \%$ of respondents said they would use the services if required (13\% said 'No' and 14\% were 'Unsure'). The reasons given for not using the services were to do with a feeling of not requiring the service rather than a fear of embarrassment or lack of knowledge. This significant decrease in the number of respondents who would not use the services, and the reasons given, suggests that the teaching was not only able to provide education about where to go for help and advice, but also succeeded in removing some of the attached stigma.

\section{Improving future teaching}

We asked what measures we could take to improve future teaching. As this was the primary aim of the questionnaire, we wanted to allow an explicit opportunity for the pupils to give feedback. Feedback was fairly mixed, with both negative and positive comments. Whilst many respondents said they had enjoyed the sessions and had no suggestions for improvements, others suggested that more discussion and interactive teaching would have been beneficial. One way of approaching this would be to have smaller groups for discussion, which may help to maintain focus on the session. Other pupils highlighted the fact that they didn't necessarily understand all the material and that more explanation and information would have helped. This needs to be borne in mind when planning and delivering further teaching sessions. While it is important to allow opportunities for questions, we need to remember that many young people may not be comfortable asking their questions in front of peers, so we should try to give sufficient information and minimise the need for embarrassing questions. Although this can seem patronising (one of the faults identified with the sessions), it is probably better to provide clear information rather than miss out things that to some may seem obvious. The other main theme that came out of asking for feedback was the slightly rushed nature of the sessions as there was a lot of information to cover. Several pupils suggested having more sessions, although this may not be practical. Perhaps instead we could work towards making the sessions more concise.

Teaching concerning STIs is clearly a very relevant topic for young people, however many pupils regarded it as not relevant to them, which suggests that we may need to reassess how we teach it. Case studies should not be too detached from the lives of the pupils so that their relevance is emphasised. Focusing on epidemiology and statistics pertaining to STI risk may not be helpful, both because this can emphasise an apparent 'low risk' and, as highlighted by one pupil, if you get an STI yourself, knowledge about its 
epidemiology is not especially helpful at that point. Emphasis on the transmission, symptoms and outcomes may therefore be more relevant to this particular group.

We asked the pupils to rate the overall teaching to give an impression of their level of enjoyment, usefulness and the quality of presentation. Although there was a wide range of results (pupils were asked to give a mark out of ten), overall the scores were fairly high with a mean rating of $6.92 / 10$, suggesting that generally the teaching is well received, the current format is good and any adjustments needed are fairly minor.

As our questionnaire and evaluation was designed to improve the quality of teaching delivered, we made suggestions about how teaching in future years could be improved. Delivery of teaching by medical students rather than schoolteachers was a very popular concept - and gives the students a degree of anonymity - and we believed this to be one of the strongest elements of the programme. It is important to maintain the interactive nature of the teaching; but equally, new ways for informal yet constructive interaction should explored in order to develop the relationship between pupil and medical student teacher.

Embarrassment was a significant factor holding pupils back from fully participating in the sessions. To ameliorate this issue, smaller groups can be used to discuss multiple ideas, which can then be fed back to the entire class when some of the embarrassment has dissipated. Pupils may find it easier to contribute if their ideas are only shared with a small number of people, and when they rejoin the rest of the class any ideas are presented as 'group thinking'.

It appears that the volume of information that the teachers were attempting to convey in the sessions was simply too great for many of the pupils. It would therefore be worth trying to reduce the quantity of information, making the teaching more concise yet maintaining its broad outline and scope. However, clarification and emphasis do have to be given where they are needed, especially in areas where the relevance is high and misinterpretation is common, in particular the distinctions between contraception, emergency contraception and abortion; the non-sexual routes of transmission for STIs; and, to a lesser degree, epidemiological statistics.

\section{Concluding remarks}

We have taken into account our findings in the design of our lesson plans for the next academic year. Our findings will also shape the way we deliver the lessons and allow an iterative process of quality improvement.

\section{Statements on funding and competing interests}

Funding None identified.

Competing interests None identified.

\section{Editor's note}

This essay won first prize in the 2009 Margaret Jackson Prize Essay competition, an annual competition open to undergraduate medical students who are invited to submit an essay on a topic related to contraception, reproductive and sexual health care. In addition to winning a cash prize, the prize-winning essay may also be published in the Journal of Family Planning and Reproductive Health Care at the discretion of the Editor-in-Chief, although it should be noted that prize-winning essays are not subjected to the formal peer review process that all submitted articles routinely undergo prior to acceptance and subsequent publication in the Journal.

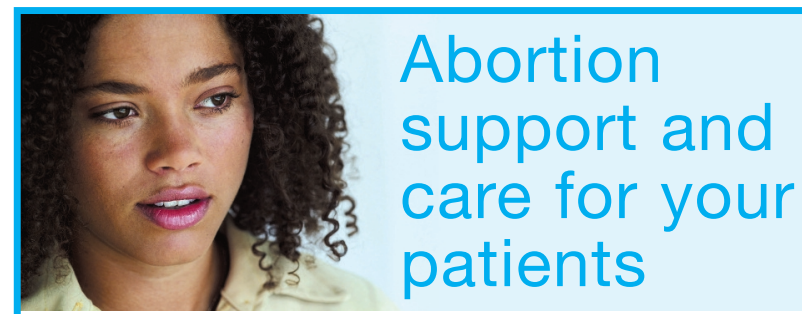

Sue Baldock

Clinical Lead - Marie Stopes International

Women who face an unplanned pregnancy often want to be seen as quickly as possible to receive supportive advice and information about their choices.

At Marie Stopes International we see over a third of all women in England and Wales seeking abortion help. As experts in this field we have

modernised abortion provision making us the first choice among health care professionals. 50,000 women a year visit our network of UK clinics for NHS abortion services.

Our organisation has received a very positive response from women in favour of the 24 hour telephone counselling and consultation service run by our experienced counsellors and specialist nurses.

$\begin{array}{ll}\text { Our services include: } & \\ \text { - Fast appointments - usually } & \begin{array}{c}\text { - Contraceptive methods } \\ \text { including LARC }\end{array} \\ \text { within } 48 \text { hours } & \text { - Post-abortion counselling } \\ \text { to } 9 \text { weeks) } & \text { - } 24 \text { hour aftercare service } \\ \text { - Surgical abortion (up to } 24 \text { weeks) } & \text { run by dedicated nurses } \\ \text { - Chlamydia screening } & \end{array}$

If you would like our abortion service referral guidelines or a free resources pack please call 02070342382

\section{4} 24 hours

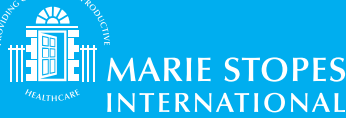

\section{Lubrication ...naturally}

SYLK natural personal lubricant for the alleviation of atrophic vaginitis is now included within the NHS Drug Tariff Part IX and available on an FP10.

Adopted and endorsed by a multiprofessional group investigating the use of vaginal dilators following pelvic radiotherapy, as well as members of the National Committee of the National Forum of Gynaecology Oncology Nurses (NFGON) and other relevant groups within the NHS, SYLK

- has a non chemical base derived from an extract of the kiwi fruit plant that effectively mimics a woman's natural secretions and is the only paraben free lubricant

- has passed cytotoxicity, sensitisation and product stability tests. The $\mathrm{pH}$ of SYLK is controlled within 4.5 to 4.7 , to equate with the vaginal environment

- is a class 1 medical device available in one $40 \mathrm{ml}$ size, sufficient for up to 150 applications

Free samples and consumer literature are readily available from:

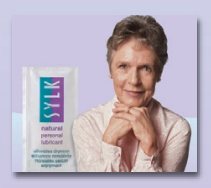
SYLK Limited FREEPOST, PO Box 340 Rickmansworth, WD3 5WD Tel: 08709506004 www.sylk.co.uk 